\title{
Erratum to: Management of osteoporosis of the oldest old
}

\author{
R. Rizzoli • J. Branco • M.-L. Brandi • S. Boonen • O. Bruyère • P. Cacoub • C. Cooper • \\ A. Diez-Perez • J. Duder • R. A. Fielding • N. C. Harvey • M. Hiligsmann • J. A. Kanis • \\ J. Petermans $・$ J. D. Ringe $\cdot$ Y. Tsouderos $・$ J. Weinman $\cdot$ J.-Y. Reginster
}

Published online: 1 August 2014

(C) International Osteoporosis Foundation and National Osteoporosis Foundation 2014

\section{Erratum to: Osteoporos Int \\ DOI 10.1007/s00198-014-2755-9}

In the affiliation of S. Boonen the city should have been given as Leuven, not Liege.

The online version of the original article can be found at http://dx.doi.org/ 10.1007/s00198-014-2755-9.

R. Rizzoli $(\bowtie)$

Service of Bone Diseases, Geneva University Hospitals and Faculty of Medicine, Geneva, Switzerland

e-mail: Rene.Rizzoli@unige.ch

\section{J. Branco}

CEDOC, Department of Rheumatology, Faculdade de Ciências

Médicas, Universidade Nova de Lisboa/CHLO, EPE-Hospital Egas

Moniz, Lisbon, Portugal

\section{M.-L. Brandi}

Department of Internal Medicine, University of Florence, Florence, Italy

\section{S. Boonen}

Katholieke Universiteit Leuven, Leuven, Belgium

O. Bruyère $\cdot$ J.-Y. Reginster

Department of Public Health, Epidemiology and Health Economics, University of Liege, Liege, Belgium

\section{P. Cacoub}

Department Hospitalo-Universitaire I2B, UPMC University of Paris 06; INSERM, UMR S 959; CNRS, UMR 7211; and AP-HP, Groupe Hospitalier Pitié-Salpêtrière, Department of Internal Medicine, Paris, France

C. Cooper $\cdot$ N. C. Harvey

MRC Lifecourse Epidemiology Unit, University of Southampton,

Southampton, UK

\section{Cooper}

NIHR Musculoskeletal Biomedical Research Unit, University of Oxford, Oxford, UK

\section{A. Diez-Perez}

Servicio de Medicina Interna y Enfermedades Infecciosas, Hospital del Mar-IMIM and RETICEF, Barcelona, Spain
J. Duder

Atlantis Healthcare, 5 Chiswick Park, 566 Chiswick High Road, London, UK

\section{R. A. Fielding}

Nutrition, Exercise Physiology and Sarcopenia Laboratory, Jean Mayer USDA Human Nutrition Research Center on Aging \& Friedman School of Nutrition Science and Policy, Tufts University, Boston, MA, USA

\section{R. A. Fielding}

Claude D. Pepper Older Americans Independence Center, Boston, MA, USA

\section{Hiligsmann}

Department of Health Services Research, School for Public Health and Primary Care (CAPHRI), Maastricht University, Maastricht, Netherlands

\section{J. A. Kanis}

WHO Collaborating Centre for Metabolic Bone Diseases, University of Sheffield, Sheffield, UK

\section{J. Petermans}

Service of Geriatrics, CHU of Liege, Liege, Belgium

\section{J. D. Ringe}

Department of General Internal Medicine, Klinikum Leverkusen University of Cologne, Cologne, Germany

Y. Tsouderos Institut de Recherches Internationales Servier, Suresnes, France

\section{J. Weinman} Institute of Pharmaceutical Sciences, Institute of Psychiatry, Kings College London \& Atlantis Healthcare, London, UK 